\title{
Molecular Mechanism of Multi-Drug Resistance in Mycobacterium tuberculosis ${ }^{\dagger}$
}

\author{
Thirumurugan Ravibalan ${ }^{1, *}$, Stefi S.M. ${ }^{2}$ \\ 1 Department of Transfusion Medicine, JIPMER, Puducherry-605006, India \\ 2 Department of Biotechnology, School of Bio and Chemical Engineering, Sathyabama \\ * Correspondence: hirumuruganphd@gmail.com; \\ $\dagger$ Presented at International e-Conference on Bioengineering for Health and Environment (ICBHE 2020)
}

Received: 5.07.2020; Revised: 10.07.2020; Accepted: 12.07.2020; Published: 15.07.2020

\begin{abstract}
In this study, we demonstrate the clinical applicability of molecular assays for the differential identification of M. tuberculosis isolates by Double Repetitive Element-PCR (DRE-PCR), Duplex PCR (DPCR), Random Amplified Polymorphic DNA-PCR (RAPD-PCR) and IS6110 flanking PCR and for the detection of specific codon mutations in antibiotic-resistant genes, rpoB and kat $G$ in 55 MDR-TB and 25 drug-susceptible clinical isolates by Multiplex PCR assays. The MAS-PCR assay was identified as the most prevalent rpoB gene mutations at codon 531 (83.6\%), followed by codon $526(12.7 \%)$, and no mutation was found in codon 516. Among the 55 MDR-TB isolates, 49 (89\%) isolates had S315T, 5 (9\%) had S315N mutations. DRE-PCR and RAPD-PCR generated similar banding of cluster III strains and suggested that MDR-TB strain genotype $C$ may be responsible for the transmission of TB infection among the study population. PCR based differential identification of $m t p 40$ and rpoB DPCR procedures identified two NTM strains among the isolates studied. Genotypic method DRE-PCR was found highly reproducible, followed by RAPD-PCR and $m t p 40$, and rpoB DPCR methods effectivelyidentified NTM infection in this region. The presence of S315T mutation in $k a t G$ gene and S531L, $\mathrm{H} 526 \mathrm{Y}$ mutations in $r p o B$ gene in MDR-TB isolates proved resistant phenotype. The simplicity of the MAS-PCR assay permits its implementation for the detection of resistance to INH and RIF in clinical laboratories in regions where this mutation is predominant among MDR-TB strains.
\end{abstract}

Keywords: Mycobacterium tuberculosis; Multidrug resistance; kat G gene; rpoB gene; MAS-PCR; PCR-RFLP; RAPD-PCR; DRE-PCR.

(C) 2020 by the authors. This article is an open-access article distributed under the terms and conditions of the Creative Commons Attribution (CC BY) license (https://creativecommons.org/licenses/by/4.0/).

\section{Funding}

This research received no external funding.

\section{Acknowledgments}

This research has no acknowledgment.

\section{Conflicts of Interest}

The authors declare no conflict of interest. 